Exp. Anim. 65(2), 109-116, 2016

\title{
-Original-
}

\section{Histomorphometry of the tibia and mandible of healthy female Wistar rats at different stages of growth}

\author{
María M. NENDA, Marianela LEWICKI, and Patricia M. MANDALUNIS \\ Department of Histology and Embryology, School of Dentistry, University of Buenos Aires, Marcelo T de Alvear \\ 2142. C1122, Buenos Aires, Argentina
}

\begin{abstract}
Female Wistar rats are frequently used in experimental models to study hormone and bone pathologies and treatments. Most experimental studies involving histomorphometric evaluation assessed long bones, and few reports also studied mandibular bone. The aim of this work was to clarify and distinguish the age-related histomorphometric changes that occur in the tibia (subchondral bone) and in the mandible (interradicular bone), and thus obtain reference histomorphometric data of healthy female Wistar rats at different growth stages. Three groups of 8 healthy female Wistar rats were euthanized at 6 (GI), 10 (GII), and 14 (GIII) weeks. The tibiae and mandible were resected and histologically processed to obtain H\&E stained sections of the tibia and the lower first molar to analyze the following histomorphometric parameters: Bone volume, trabecular width, trabecular number (Th.N) $(1 / \mathrm{mm})$, growth cartilage width, hypertrophic cartilage width and number of osteoclasts per area in the tibiae, and bone volume and number of osteoclasts per area N.Oc/mm² in the interradicular bone of the first lower molar. A significant decrease in subchondral bone volume as a result of a decrease in trabecular number and growth cartilage width was observed in 14-week-old rats. Conversely, interradicular bone volume was found to increase with age. The results highlight the importance of analyzing both types of bone to better understand the response of two different trabecular bones, contributing in turn to decision making regarding treatment strategies and disease management.

Key words: bone histomorphometry, healthy Wistar rat, long bone, mandibular bone
\end{abstract}

\section{Introduction}

Experimental animal models play an important role in gaining knowledge on the etiology, physiopathology, and diagnosis, of a number of bone disease, as well as useful preventive techniques and therapies. These models allow obtaining detailed, standardized data that would be difficult to gather from clinical experimental studies, given the differences among patients. The choice of an in vivo experimental model is determined by a number of factors, including its reliability, reproducibility, and feasibility, as well as other issues, such as those associ- ated with equipment needs and research costs, both of which must inevitably be considered [11]. Female Wistar rats are frequently used in experimental models for the study of hormone and bone pathologies and treatments [2]. These models typically involve ovariectomy (Ovx) in order to induce estrogen deficiency, which results in bone loss (osteoporosis) [15, 17]. The Ovx-induced changes in bone can be analyzed using biochemical markers, densitometric parameters, and/or histomorphometric parameters [30]. The majority of experimental studies in the literature involving histologic and histomorphometric evaluation to analyze bone

(Received 8 July 2015 / Accepted 13 October 2015 / Published online in J-STAGE 13 November 2015)

Address corresponding: P. M. Mandalunis, Department of Histology and Embryology, School of Dentistry, University of Buenos Aires, Marcelo T. de Alvear 2142. C1122AAH. C.A.B.A .Argentina

C2016 Japanese Association for Laboratory Animal Science 
biology, evaluate the trabecular bone of long bones (tibia and/or femur). The results of these studies have served as the bases for drawing conclusions regarding the response of the entire skeletal, despite the skeleton being composed of different types of bone.

Only a few studies performed histomorphometric determinations of mandibular bone to investigate the effect of systemic diseases and/or treatment with different drugs on this type of bone $[10,18,31,37]$. There are no studies reporting histomorphometric data of mandibular bone of healthy female Wistar rats at different stages of growth.

The tibia and femur are studied histologically and histomorphometrically by evaluating the subchondral bone and the growth cartilage $[8,12]$, since these regions reflect bone modeling and remodeling dynamics $[1,13]$. The mandible is assessed by analyzing the interradicular bone of the first lower molar [23].

Whereas the tibia and femur are long bones, interradicular bone is a craniofacial bone. These two types of bone have different embryologic origin, ossification and function, and are subjected to very different mechanical loads. Long bones, such as the tibia and femur, develop from the lateral somatic mesoderm/mesenchyme towards the end of the fourth week of gestation [4]. Long bone formation first appears as a condensation of mesenchymal cells in the central nucleus located in the proximal region of the limb buds, which are destined to form cartilage. These cells differentiate into chondroblasts, forming the hyaline cartilaginous model of the future bone. The bones formed by this process, termed endochondral ossification, are designed to exert mechanical functions: movement and force [26].

The mandible is of ectomesenchymal origin and derives from the first branchial arch [22]. The cartilage of the first arch (Meckel's cartilage) forms the lower jaw in primitive vertebrates and in humans; it has a close positional relationship to the developing mandible, but makes no contribution to it. During the sixth week of embryonic development, a condensation of mesenchyma occurs in the angle formed by the division of the inferior alveolar nerve and its incisor and mental branches. At seven weeks, intramembranous ossification begins in this condensation, forming the first bone of the mandible [24]. The functions of the mandible are mastication, phonation, and deglutition.

An interesting study published by Mavropoulos et al. in 2007 found mandibular alveolar bone to be less sensi- tive to either protein undernutrition or Ovx than the proximal tibia spongiosa. The authors hypothesized that the different origin, ossification, and function of long bones and the mandible explain the differences in their response to stimuli [21].

Given the importance of histomorphometry to evaluate bone biology, and the contribution of experimental studies to the clinical practice and to the advancement in therapeutics used in medicine and in different fields of dentistry, such as implantology, orthodontics, prosthetics, among others, it is essential to have reference data of histomorphometric parameters not only of the tibia and/ or femur but also of mandibular interradicular bone of Wistar rats. In view of the above, the aim of the present work was to to clarify and distinguish the age-related histomorphometric changes that occur in the tibia (subchondral bone) and in the mandible (interradicular bone), and thus obtain reference histomorphometric data on healthy female Wistar rats at different stages of growth: Prepuberty (at age 6 weeks), puberty (at age 10 weeks), sexually maturity (at age 14 weeks).

\section{Materials and Methods}

\section{Experimental animals}

Healthy outbred female Wistar rats were used. The animals were free of specific pathogens as evidenced by regular health monitoring. Twenty-four female weanling Wistar rats (body weight 60-80 g) were assigned to one of three groups of 8 animals. All the rats were housed in galvanized steel wire cages with sterile wood chip bedding, at $21-24^{\circ} \mathrm{C}$ and $56 \%$ humidity, on a $12 \mathrm{~h}$ light-dark cycle, and were fed standard extruded chow with 23\% protein (Cooperación, ACA Nutrición, Buenos Aires, Argentina) and water at libitum. The cage bedding was changed three times a week. The animals were weighed every week throughout the experiment, and immediately before euthanasia. Under anesthesia with $2 \%$ xylazine $5 \mathrm{mg} / \mathrm{kg}$ (Kensol, Konig) and $5 \%$ ketamine, 50 $\mathrm{mg} / \mathrm{kg}$ (Ketamine 50, Holliday Laboratory), the rats were euthanized by intracardiac injection of $0.2 \mathrm{ml}$ of pentobarbital sodium diphenylhydantoin (Euthanyle, Laboratorio Brouwer Laboratory) as follows: Group 1: 6 weeks (pre-pubertal), Group II: 10 weeks (pubertal), and Group III: 14 weeks (sexually mature). The experimental protocol was approved by the Ethics Committee of the School of Dentistry (28/11/2012-38), University of Buenos Aires Argentina, and is in keeping with the Na- 


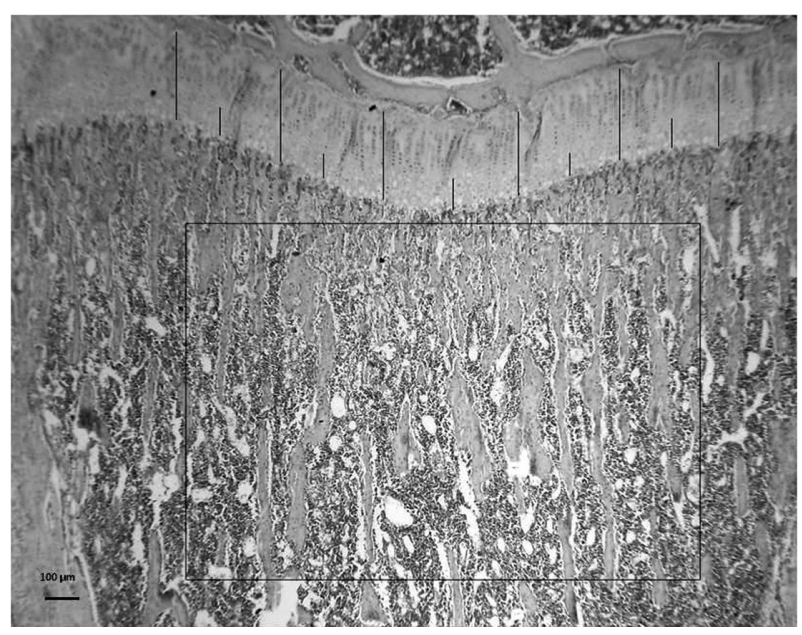

Fig. 1. The figure shows the area of subchondral bone used to measure Bone volume (BV/TV)(\%) (H\&E, 25X), and the 6 sites where Growth cartilage width (GPC.Wi) $(\mu \mathrm{m})$ and Hypertrophic cartilage width (HpZ.Wi) $(\mu \mathrm{m})$ were determined. H\&E 40X.

tional Institutes of Health Guidelines for the Care and Use of Laboratory Animals.

\section{Histology}

Following euthanasia, the tibiae and mandible were resected. The specimens were fixed in $4 \%$ buffered formalin at room temperature, decalcified in $10 \%$ ethylenediaminetetraacetic acid (EDTA) $\mathrm{pH}$ 7, for 30 days, dehydrated, and embedded in paraffin to obtain $7-8 \mu \mathrm{m}$ sections: longitudinal sections of the tibia and mesiodistally oriented sections of the lower first molar. The sections were stained with H\&E. Digital microphotographs of the sections were obtained in order to perform the histomorphometric studies, using Image pro plus 4.5 software.

\section{Histomorphometric parameters}

The following histomorphometric parameters [25] were determined in the tibiae:

- Bone volume (BV/TV) (\%): The fraction of total volume (bone tissue + bone marrow) corresponding to trabecular bone was measured in an area measuring $1.89 \mathrm{~mm}^{2}$ and expressed as a percentage (Fig. 1).

- Trabecular width (Tb.Wi) $(\mu \mathrm{m})$.

- Trabecular number (Tb.N) (1/mm).

- Growth cartilage width (GPC.Wi) $(\mu \mathrm{m})$ was measured at 6 equidistant points and the values were averaged to obtain a final result for each section (Fig. 1).
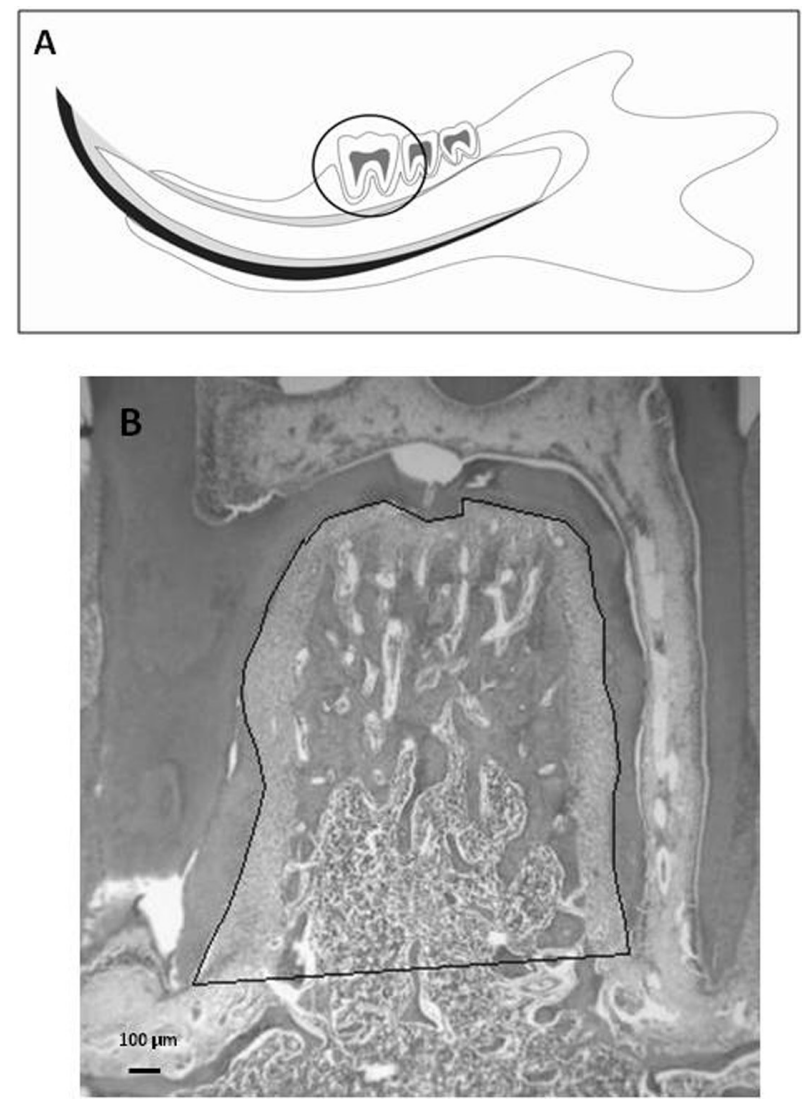

Fig. 2. Schematic drawing of Wistar rat mandible showing localization of the first lower molar (A). Bone volume (BV/TV) was measured in the interradicular region of the first lower molar (B). H\&E, 40X.

- Hypertrophic cartilage width (HpZ.Wi) $(\mu \mathrm{m})$ was measured at 6 equidistant points and the values were averaged to obtain a final result for each section. The hypertrophic zone is limited by the first hypertrophic chondrocyte on the upper side and by the first mixed trabeculae on the lower side (Figs. 1 and 4).

- Number of Osteoclasts per area, in subchondral bone $\left(\mathrm{N} . \mathrm{Oc} / \mathrm{mm}^{2}\right.$ ): Cells presenting 2 or more nuclei and that were close to trabeculae were considered osteoclastic cells.

The following histomorphometric parameters [28] was determined in the interradicular bone of the first lower molar:

- Bone volume (BV/TV) (\%): The fraction of total volume (trabecular bone + bone marrow + periodontal ligament) corresponding to trabecular bone was calculated and expressed as a percentage (Figs. $2 \mathrm{~A}$ and B). - Number of Osteoclasts per area, in interradicular bone $\left(\mathrm{N} . \mathrm{Oc} / \mathrm{mm}^{2}\right.$ ): Cells presenting 2 or more nuclei and 

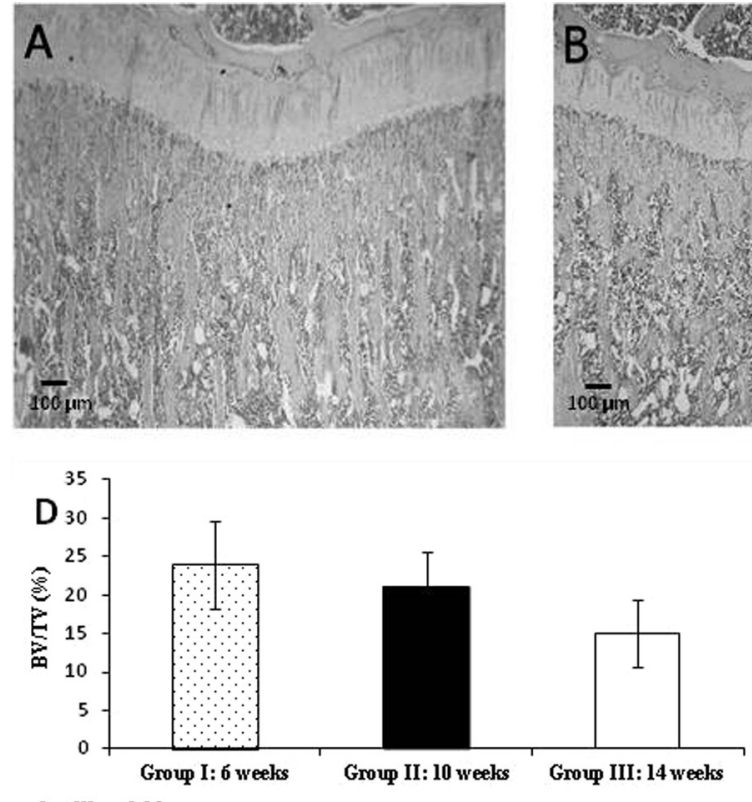

Ivs III, $\mathrm{ps} 0.05$

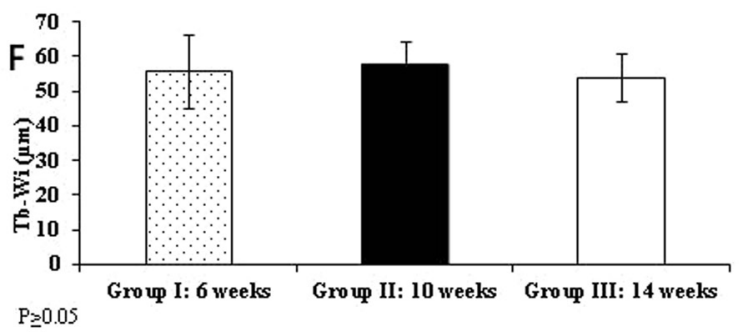

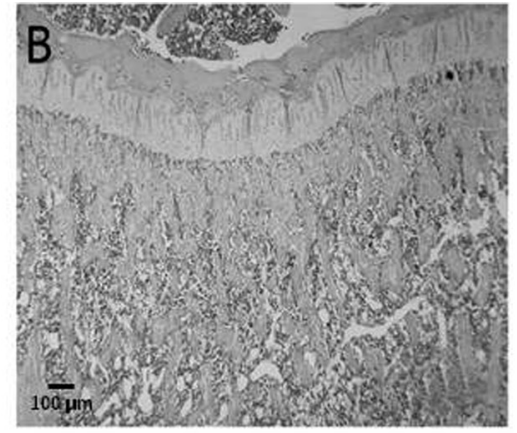
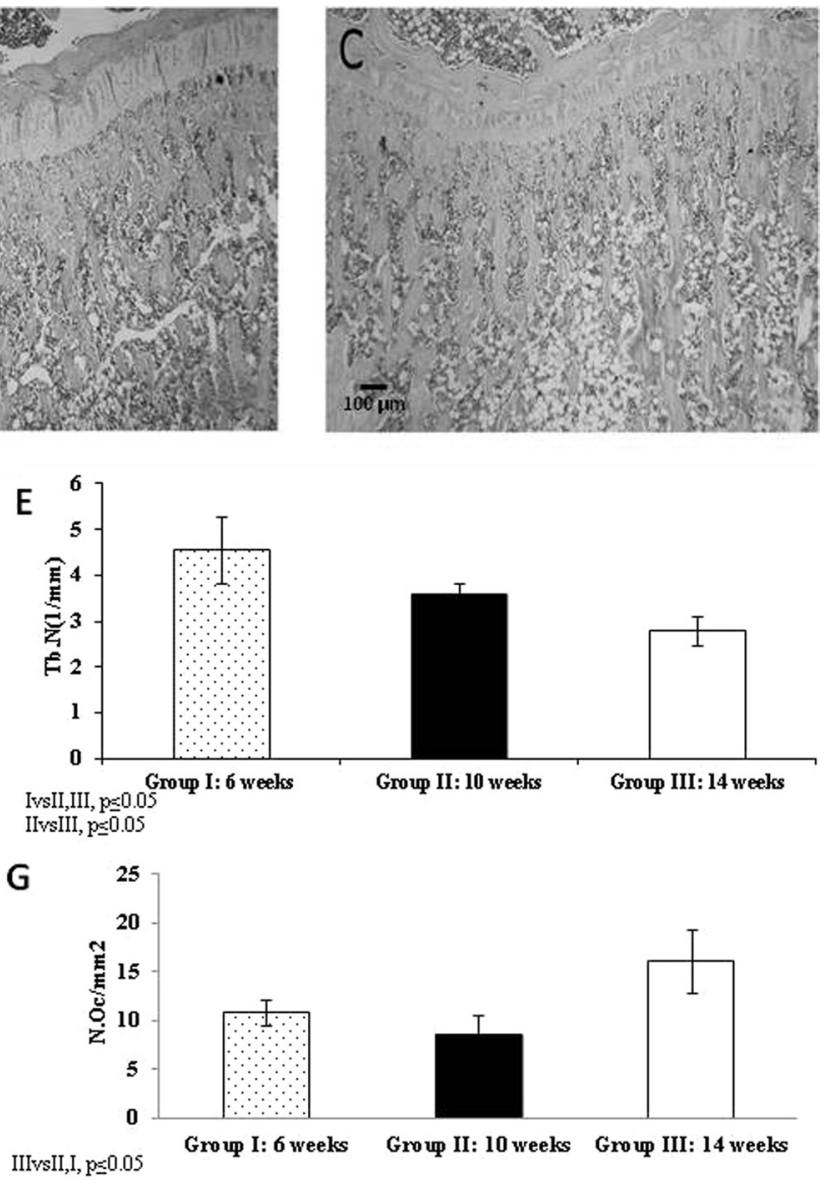

Fig. 3. Microphotographs of tibial subchondral bone sections of different aged animals: 6-week-old animals (A); 10-week-old animals (B); 14-week-old animals (C). The images clearly show a decrease in subchondral bone volume with age. H\&E, 40X. The graphs show Bone Volume (BV/TV) (\%) (D), Trabecular number (Tb.N)(1/mm) (E), trabecular Width (Tb.Wi) $(\mu \mathrm{m})(\mathrm{F})$ and osteoclast number $\left(\mathrm{N} . \mathrm{Oc} / \mathrm{mm}^{2}\right)(\mathrm{G})$ in subchondral bone.

that were close to trabeculae were considered osteoclastic cells.

\section{Statistical analysis}

The results were statistically analyzed using ANOVA and Bonferroni's test. Statistical significance was set at a value of $P<0.05$.

\section{Results}

Average weight of 6-week-old, 10-week-old, and 14week-old animals was $137 \pm 12,205 \pm 15$, and $245 \pm 7.5$ respectively, showing a significant age-dependent increase in body weight $(P<0.05)$.

\section{Tibiae}

The microphotographs and graphs in Fig. 3 show sub- chondral bone volume and trabecular bone parameters (trabecular width and trabecular number). All the images consistently show an age related decrease in bone volume BV/TV (\%) (GI: 6-week-old rats: $24 \pm 5.7$, GII: 10 -week-old rats: $21 \pm 4.7$, and GIII: 14 - week-old rats: $15 \pm 4.4$; GI vs GII $P \leq 0.05)$ resulting from a decrease in trabecular number (Tb.N) $(1 / \mathrm{mm})$ (GI: 6-week-old rats: $4.56 \pm 0.74$, GII: 10 -week-old rats: $3.60 \pm 0.25$, and GIII: $14-$ week-old rats: $2.80 \pm 0.32$ GI vs GII, GIII and GII vs GIII $P \leq 0.05)$. No significant differences in trabecular width (Tb.Wi) $(\mu \mathrm{m})$ were observed among groups (GI: 6-week-old rats: $55.8 \pm 10.7$, GII: 10-weekold rats: $58 \pm 6.4$, and GIII:14- week-old rats: $54 \pm 6.9$, $P>0.05)$. The results showed an increase in osteoclast number N.Oc/ $\mathrm{mm}^{2}$ (GI: 6-week-old rats: $10.8 \pm 1.3$, GII: 10-week-old rats: $8.5 \pm 2.14$, and GIII: 14 - week-old rats: $16.1 \pm 3.24$ GI and GII vs GIII, $P \leq 0.05$ ), an indica- 

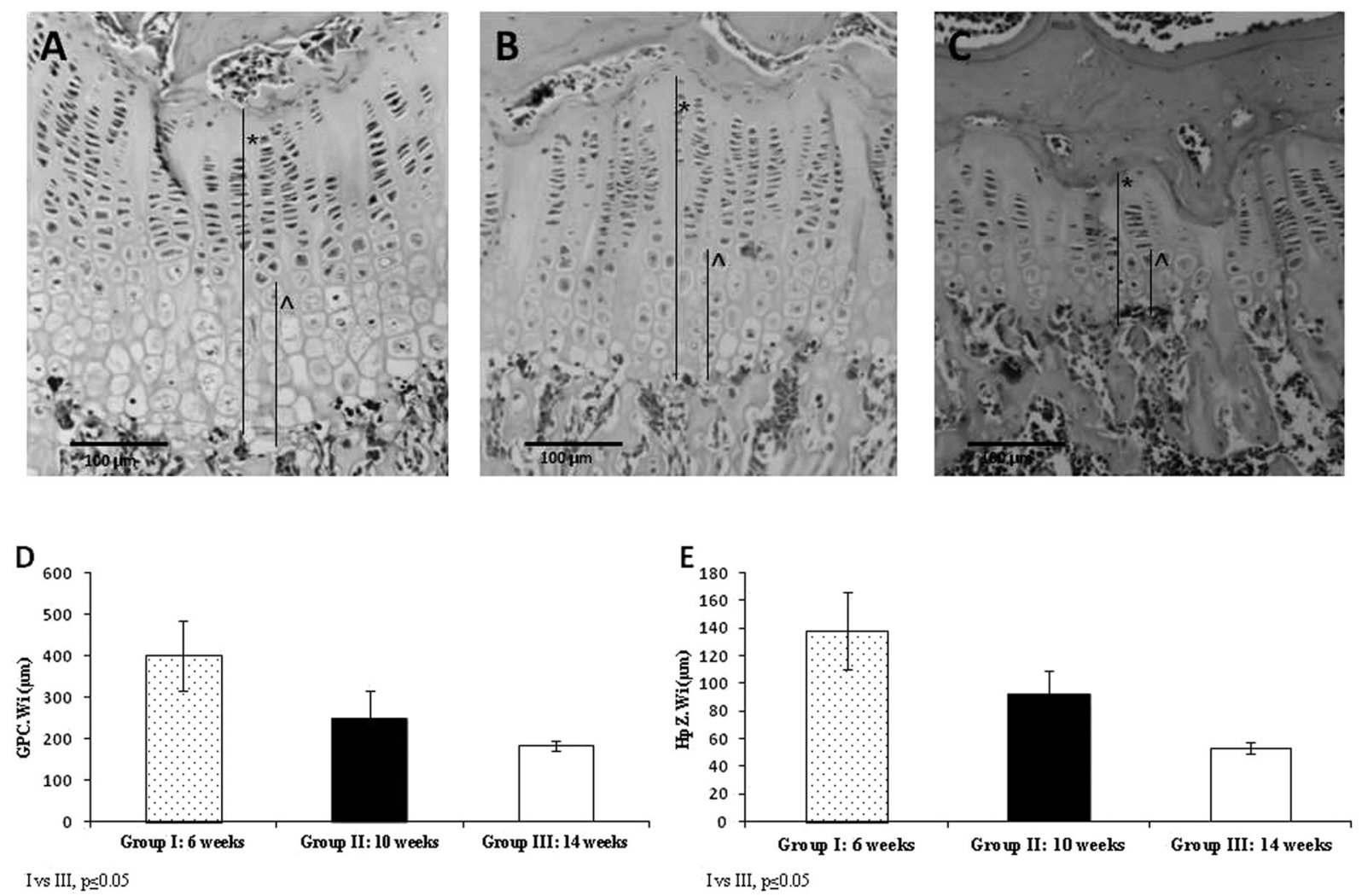

Fig. 4. Microphotographs of growth plate cartilage sections of different aged animals: 6-week-old animals (A); 10-week-old animals (B); 14-week-old animals (C). The images clearly show a decrease in growth plate cartilage width with age. H\&E, 100X. The graphs show the significant difference in Tibial Growth Cartilage (GPC.Wi) ( $\mu \mathrm{m})(\mathrm{D})$ and Hypertrophic Cartilage width $\left(\mathrm{HpZ}\right.$. Wi) $(\mu \mathrm{m})(\mathrm{E})$. The lines show GPC. Wi $\left(^{*}\right)$ and Hpz.Wi $\left(^{\wedge}\right)$.

tion of bone resorption, concomitant to the significant decrease in bone volume between GI and GIII.

Tibial growth cartilage (GPC.Wi) $(\mu \mathrm{m})$ and hypertrophic cartilage width (HpZ. Wi) $(\mu \mathrm{m})$ are shown in Fig. 4. A significant age-related decrease in both GPC.Wi $(\mu \mathrm{m})(6$-week-old rats: $402 \pm 85,10$-week-old rats: 251 \pm 64 , and 14-week-old rats: $185 \pm 12)$ and $\mathrm{HpZ}$. Wi $(\mu \mathrm{m})$ (6-week-old rats: $138 \pm 28,10$-week-old rats: $92 \pm 17$, and 14-week-old rats: $53 \pm 4$ ) was observed. The differences between 6-week-old and 14-week-old animals were statistically significant $(P \leq 0.05)$.

\section{Interradicular bone of the first lower molar}

As shown in Fig. 5, and conversely to that observed in subchondral bone, interradicular bone volume was found to increase in 10- and 14- week-old rats compared to 6-week-old animals. BV/TV (\%) (GI: 6-week-old rats: $36 \pm 5.8$, GII: 10 -week-old rats: $45 \pm 6.5$, and GIII:14week-old rats: $50 \pm 6.0$ ). Statistically significant differences were observed between 6-week-old animals and
10 -week and 14-week-old animals $(P \leq 0.05)$. A significant increase in bone volume concomitant with a decrease in osteoclast number (N.Oc/ $/ \mathrm{mm}^{2}$ ) was observed in sexually mature rats (GI: 6-week-old rats: $4.34 \pm 1.37$, GII: 10 -week-old rats: $2.96 \pm 1.26$, and GIII:14- weekold rats: $2.24 \pm 1.41$, GI vs GIII $P \leq 0.05$ ).

\section{Discussion}

The results of the present study show significant changes in histomorphometric parameters of Wistar rat tibia and interradicular bone of the first lower molar at different stages of growth: prepubertal (age 6 weeks), pubertal (age 10 weeks), sexually mature (age 14 weeks). prepuberty (age 6 weeks), puberty (age 10 weeks), sexually maturity (age 14 weeks). There are no reports in the literature comparing bone histomorphometric parameters of tibial subchondral bone and molar interradicular bone of prepubertal, pubertal, and sexually mature healthy female Wistar rats. Although both bones 

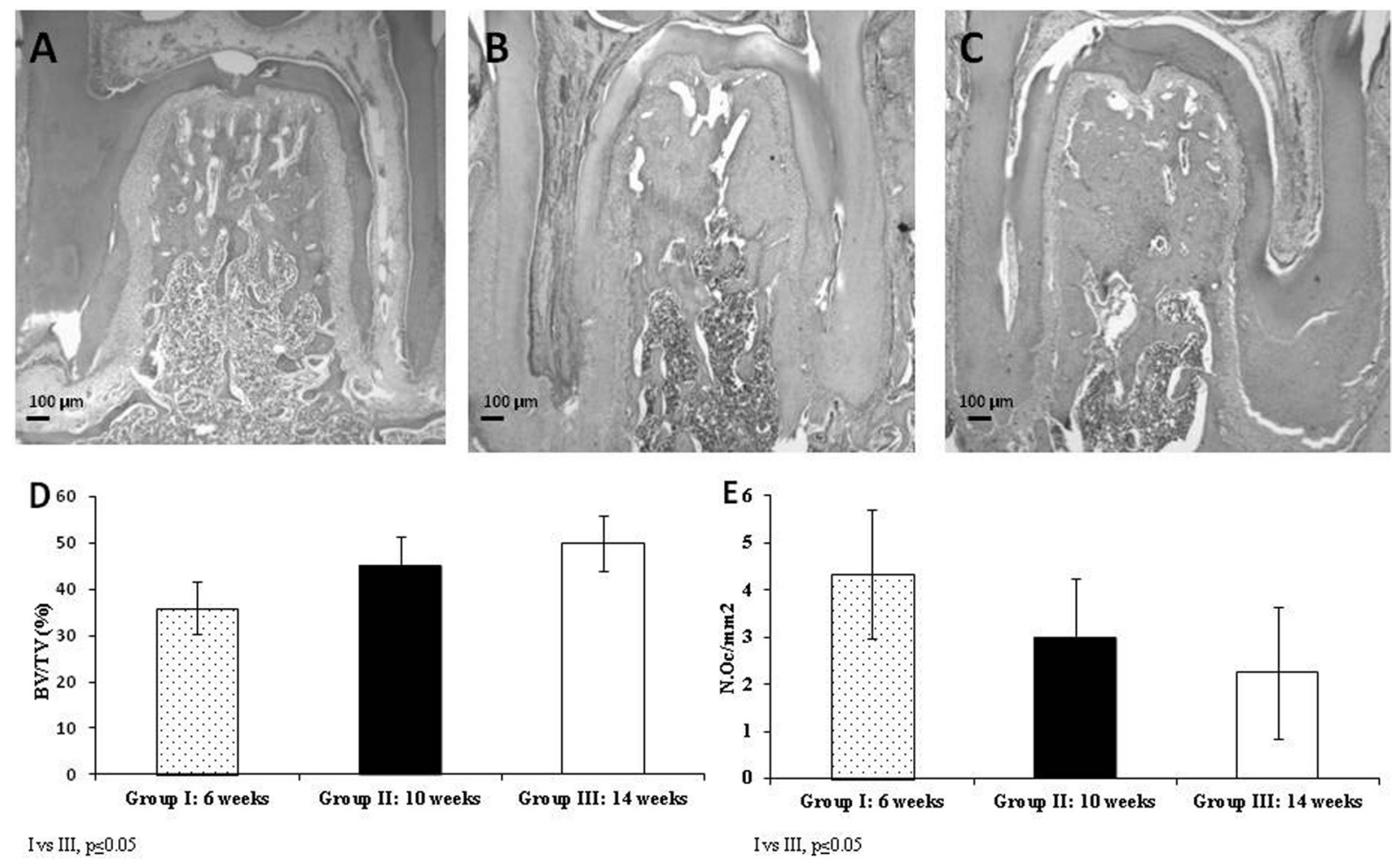

Ivs III, $\mathrm{p} \leq 0.05$

Fig. 5. Microphotographs of first lower molar interradicular bone sections of different aged animals. 6-week-old animals (A); 10-week-old animals (B); 14-week-old animals (C). The images show an increase in interradicular bone volume with age. H\&E, 40X. Graph D shows bone volume and Graph E shows osteoclast number (N.Oc/ $/ \mathrm{mm}^{2}$ ) in interradicular bone.

consist of compact and trabecular bone and are part of the skeleton, their function and dynamics differ.

A significant decrease in subchondral bone volume as a result of a decrease in trabecular number, a significant increase in osteoclast number indicating an increase in bone resorption, and a significant decrease in total growth cartilage width and hypertrophic cartilage width reflecting a decrease in bone formation, were observed in sexually mature Wistar rats (14-weeks old). Our observations are in keeping with data reported in the literature. Roach et al. and Walker et al. showed an agerelated decrease in growth cartilage with in healthy rats directly associated with cessation of growth [27, 35]. In addition, Chen et al. and Ijiri et al. reported similar findings in rats subjected to immobilization $[5,16]$.

Unlike subchondral bone, interradicular bone volume was found to increase in sexually mature female rats; this finding was associated with a lower osteoclast number, an indication of lower bone resorption.

Mechanical stress is known to be an important factor in the regulation of bone remodeling. As regards the type of mechanical load, the mandible is subjected to me- chanical loading during mastication [20]; the femur and tibia are the weight bearing bones involved in movement and locomotion. Although both types of bones are subjected to mechanical loads, the forces generated during walking are almost half those to which alveolar bone is exposed during mastication [7, 19].

As mentioned in the Introduction section, Mavropoulus et al. [21] found mandibular alveolar bone to be less sensitive to protein undernutrition and/or estrogen deprivation than the proximal tibia spongiosa. The authors hypothesize that the mechanical loading of the alveolar process during mastication may protect the alveolar bone from the detrimental effects observed in other skeletal sites.

There is a direct relation between bone architecture and mechanical forces: whereas bone mass is increased by exercise, it decreases through lack of exercise and immobility. There is normally a balance between osteoblasts that synthesize bone matrix and osteoclasts in charge of resorption in the bone remodeling process [14, 36].

Alveolar bone has a high bone turn-over rate, and 
normally undergoes resorption on one side of the socket and bone formation on the opposite side as the tooth migrates [34].

Taking into account findings observed by Braun et al. [3] in male and female subjects, a possible explanation to the age-related increase in interradicular bone volume observed in the present study might be associated the greater muscle mass development that occurs during growth.

Another possible explanation to the observed increase in interradicular bone volume could be associated with age-related changes in salivary flow and composition [6, 33]. These changes might result in increased mechanical forces during mastication, with an ensuing increase in their anabolic effect on alveolar bone, which would in turn lead to higher bone volume.

In addition, although there is no scientific evidence to date, the differences observed when comparing age-related changes in subchondral and interradicular bone volume might be associated with their different embryologic origin and ossification process [32].

Systemic diseases, such as osteoporosis, hyperparathyroidism, and Paget's disease, affect all bones, including the jaws. Nevertheless, in response to external stimuli, including ovariectomy and malnutrition, rat mandibles lose significantly less trabecular bone than tibia primary spongiosa, suggesting different dynamics of the two bones $[9,10]$. Cherubism, hyperparathyroid jaw tumor syndrome, and bisphosphonate-related osteonecrosis of the jaws (BRONJ) affect only the maxilla and mandible, also suggesting different dynamics of the jaws and long bones [19, 21, 28, 29].

Experimental studies on the effects of systemic disease on bone biology usually focus on subchondral bone of the tibia or trabecular bone in vertebrae, and few include evaluation of such effects on mandibular bone. It must be pointed out that subchondral bone, where histomorphometric measurements are usually performed, develops from the growth of the epiphyseal plate. Whereas many of the species used for experimental research show synchrony between the onset of sexual maturity and growth plate closure, growth plates do not close and longitudinal bone growth continues long after sexual maturity in rodents. Therefore, the results obtained from subchondral bone of rats must be interpreted with care.

The results of the present study show different agerelated changes in each type of bone, highlighting the importance of analyzing both in order to gain a broader understanding of the implications of a given disease/ condition on bone. Evaluating both long and craniofacial bones will contribute data on the particular response of each bone type to a given condition and ageing, contributing in turn to decision making regarding medical and dental treatment strategies and disease management.

\section{Acknowledgments}

The authors wish to thank Ana María Gómez, Mariela Lacave and Ivana Sánchez for their technical assistance. This work was funded by Grant 20020120100190BA, University of Buenos Aires.

\section{References}

1. Bagi, C.M., Wilkie, D., Georgelos, K., Williams, D., and Bertolini, D. 1997. Morphological and structural characteristics of the proximal femur in human and rat. Bone 21: 261-267. [Medline] [CrossRef]

2. Barlet, J.P., Coxam, V., Davicco, M.J., and Gaumet, N. 1994. [Animal models of post-menopausal osteoporosis]. Reprod. Nutr. Dev. 34: 221-236 (in French) . [Medline] [CrossRef]

3. Braun, S., Hnat, W.P., Freudenthaler, J.W., Marcotte, M.R., Hönigle, K., and Johnson, B.E. 1996. A study of maximum bite force during growth and development. Angle Orthod. 66: 261-264. [Medline]

4. Carlson, B. 2007. A Textbook Human Embryology and Developmental Biology. 3th ed. Elsevier Mosby Editor, St Louis, Missouri, USA.

5. Chen, M.M., Jee, W.S., Ke, H.Z., Lin, B.Y., Li, Q.N., and Li, X.J. 1992. Adaptation of cancellous bone to aging and immobilization in growing rats. Anat. Rec. 234: 317-334. [Medline] [CrossRef]

6. Choi, J.S., Park, I.S., Kim, S.K., Lim, J.Y., and Kim, Y.M. 2013. Analysis of age-related changes in the functional morphologies of salivary glands in mice. Arch. Oral Biol. 58: 1635-1642. [Medline] [CrossRef]

7. Daegling, D.J. and Hylander, W.L. 1997. Occlusal forces and mandibular bone strain: is the primate jaw "overdesigned"? J. Hum. Evol. 33: 705-717. [Medline] [CrossRef]

8. Dempster, D.W., Birchman, R., Xu, R., Lindsay, R., and Shen, V. 1995. Temporal changes in cancellous bone structure of rats immediately after ovariectomy. Bone 16: 157161. [Medline] [CrossRef]

9. Esteves, C.M., Moraes, R.M., Gomes, F.C., Marcondes, M.S., Lima, G.M., and Anbinder, A.L. 2015. Ovariectomyassociated changes in interradicular septum and in tibia metaphysis in different observation periods in rats. Pathol. Res. Pract. 211: 125-129. [Medline] [CrossRef]

10. Fujita, Y., Watanabe, K., Uchikanbori, S., and Maki, K. 2011. Effects of risedronate on cortical and trabecular bone of the mandible in glucocorticoid-treated growing rats. Am. J. Orthod. Dentofacial Orthop. 139: e267-e277. [Medline] [CrossRef] 
11. Giardino, R., Fini, M., Giavaresi, G., Mongiorgi, R., Gnudi, S., and Zati, A. 1993. Experimental surgical model in osteoporosis study. Boll. Soc. Ital. Biol. Sper. 69: 453-460. [Medline]

12. Goldring, M.B., Tsuchimochi, K., and Ijiri, K. 2006. The control of chondrogenesis. J. Cell. Biochem. 97: 33-44. [Medline] [CrossRef]

13. Horton, J.A., Bariteau, J.T., Loomis, R.M., Strauss, J.A., and Damron, T.A. 2008. Ontogeny of skeletal maturation in the juvenile rat. Anat. Rec. (Hoboken) 291: 283-292. [Medline] [CrossRef]

14. Huiskes, R., Ruimerman, R., van Lenthe, G.H., and Janssen, J.D. 2000. Effects of mechanical forces on maintenance and adaptation of form in trabecular bone. Nature 405: 704-706. [Medline] [CrossRef]

15. Inada, M., Matsumoto, C., and Miyaura, C. 2011. [Animal models for bone and joint disease. Ovariectomized and orchidectomized animals]. Clin. Calcium 21: 164-170 (in Japanese). [Medline]

16. Ijiri, K., Ma, Y.F., Jee, W.S., Akamine, T., and Liang, X. 1995. Adaptation of non-growing former epiphysis and metaphyseal trabecular bones to aging and immobilization in rat. Bone 17:(Suppl): 207S-212S. [Medline] [CrossRef]

17. Ishihara, A., Sasaki, T., Debari, K., Furuya, R., Kawawa, T., Ramamurthy, N.S., and Golub, L.M. 1999. Effects of ovariectomy on bone morphology in maxillae of mature rats. $J$. Electron Microsc. (Tokyo) 48: 465-469. [Medline] [CrossRef]

18. Jiang, G., Matsumoto, H., Yamane, J., Kuboyama, N., Akimoto, Y., and Fujii, A. 2004. Prevention of trabecular bone loss in the mandible of ovariectomized rats. J. Oral Sci. 46: 75-85. [Medline] [CrossRef]

19. Knoell, A.C. 1977. A mathematical model of an in vitro human mandible. J. Biomech. 10: 159-166. [Medline] [CrossRef]

20. Mavropoulos, A., Kiliaridis, S., Bresin, A., and Ammann, P. 2004. Effect of different masticatory functional and mechanical demands on the structural adaptation of the mandibular alveolar bone in young growing rats. Bone 35: 191-197. [Medline] [CrossRef]

21. Mavropoulos, A., Rizzoli, R., and Ammann, P. 2007. Different responsiveness of alveolar and tibial bone to bone loss stimuli. J. Bone Miner. Res. 22: 403-410. [Medline] [CrossRef]

22. Mina, M. 2001. Regulation of mandibular growth and morphogenesis. Crit. Rev. Oral Biol. Med. 12: 276-300. [Medline] [CrossRef]

23. Moriya, Y., Ito, K., and Murai, S. 1998. Effects of experimental osteoporosis on alveolar bone loss in rats. J. Oral Sci. 40: 171-175. [Medline] [CrossRef]

24. Nanci, A.2003.Ten Cate's Oral Histology. 6th ed. Elsevier Mosby Editor. St Louis, Missouri, USA.

25. Parfitt, A.M., Drezner, M.K., Glorieux, F.H., Kanis, J.A.,
Malluche, H., Meunier, P.J., Ott, S.M., and Recker, R.R 1987. Bone histomorphometry: standardization of nomenclature, symbols, and units. Report of the ASBMR Histomorphometry Nomenclature Committee. J. Bone Miner. Res. 2: 595-610. [Medline] [CrossRef]

26. Provot, S. and Schipani, E. 2005. Molecular mechanisms of endochondral bone development. Biochem. Biophys. Res. Commun. 328: 658-665. [Medline] [CrossRef]

27. Roach, H.I., Mehta, G., Oreffo, R.O., Clarke, N.M., and Cooper, C. 2003. Temporal analysis of rat growth plates: cessation of growth with age despite presence of a physis. $J$. Histochem. Cytochem. 51: 373-383. [Medline] [CrossRef]

28. Ruggiero, S.L., Mehrotra, B., Rosenberg, T.J., and Engroff, S.L. 2004. Osteonecrosis of the jaws associated with the use of bisphosphonates: a review of 63 cases. J. Oral Maxillofac. Surg. 62: 527-534. [Medline] [CrossRef]

29. Simonds, W.F., James-Newton, L.A., Agarwal, S.K., Yang, B., Skarulis, M.C., Hendy, G.N., and Marx, S.J. 2002. Familial isolated hyperparathyroidism: clinical and genetic characteristics of 36 kindreds. Medicine (Baltimore) 81: 1-26 (Baltimore). [Medline] [CrossRef]

30. Slyfield, C.R., Tkachenko, E.V., Wilson, D.L., and Hernandez, C.J. 2012. Three-dimensional dynamic bone histomorphometry. J. Bone Miner. Res. 27: 486-495. [Medline] [CrossRef]

31. Tanaka, M., Toyooka, E., Kohno, S., Ozawa, H., and Ejiri, S. 2003. Long-term changes in trabecular structure of aged rat alveolar bone after ovariectomy. Oral Surg. Oral Med. Oral Pathol. Oral Radiol. Endod. 95: 495-502. [Medline] [CrossRef]

32. Teófilo, J.M., Azevedo, A.C., Petenusci, S.O., Mazaro, R., and Lamano-Carvalho, T.L. 2003. Comparison between two experimental protocols to promote osteoporosis in the maxilla and proximal tibia of female rats. Pesqui. Odontol. Bras. 17: 302-306. [Medline] [CrossRef]

33. Tomita, Y., Miyake, N., and Yamanaka, S. 2007. Phospholipid profiles in the salivary glands of rats of different ages. J. Oleo Sci. 56: 369-375. [Medline] [CrossRef]

34. Vignery, A. and Baron, R. 1980. Dynamic histomorphometry of alveolar bone remodeling in the adult rat. Anat. Rec. 196: 191-200. [Medline] [CrossRef]

35. Walker, K.V. and Kember, N.F. 1972. Cell kinetics of growth cartilage in the rat tibia. II. Measurements during ageing. Cell Tissue Kinet. 5: 409-419. [Medline]

36. Weinreb, M., Rodan, G.A., and Thompson, D.D. 1991. Depression of osteoblastic activity in immobilized limbs of suckling rats. J. Bone Miner. Res. 6: 725-731. [Medline] [CrossRef]

37. Yang, J., Pham, S.M., and Crabbe, D.L. 2003. Effects of oestrogen deficiency on rat mandibular and tibial microarchitecture. Dentomaxillofac. Radiol. 32: 247-251. [Medline] [CrossRef] 